\title{
Os desafios da prática odontológica frente à COVID-19: uma revisão de literatura
}

The challenges of dental praticte in front of COVID-19: a literature review

Los desafíos de la práctica odontológica ante el COVID-19: una revisión de la literatura

Ana Beatriz Rodrigues MOURA

Curso de Graduação em Odontologia. Centro de Saúde e Tecnologia Rural, Universidade Federal de Campina Grande (UFCG) 58708-110 Patos - PB, Brasil

https://orcid.org/0000-0003-0006-148X

Vitor Nascimento GOES

Curso de Graduação em Odontologia. Centro de Saúde e Tecnologia Rural, Universidade Federal de Campina Grande (UFCG) 58708-110 Patos - PB, Brasil

https://orcid.org/0000-0001-5163-1126

Júlia Tavares PALMEIRA

Curso de Graduação em Odontologia. Centro de Saúde e Tecnologia Rural, Universidade Federal de Campina Grande (UFCG) 58708-110 Patos - PB, Brasil https://orcid.org/0000-0002-4593-8954

Julliana Cariry Palhano FREIRE

Departamento de Odontologia de Campina Grande, Universidade Estadual da Paraíba (UEPB) 58429-500 Campina Grande - PB, Brasil https://orcid.org/0000-0001-7652-102X

Eduardo DIAS-RIBEIRO

Departamento de Cirurgia e Traumatologia Bucomaxilofacial, Universidade Federal da Paraíba (UFPB)

58051-900 João Pessoa - PB, Brasil

https://orcid.org/0000-0002-6321-4159

\section{Resumo}

Introdução: Diante da pandemia de COVID-19, o cirurgião-dentista assim como os demais profissionais de saúde são os mais expostos ao vírus, o que exige maior biossegurança nos atendimentos. Objetivo: Dentro desse contexto, o presente trabalho tem como objetivo avaliar os desafios da prática odontológica frente ao cenário de pandemia atual, enfatizando a atuação do cirurgião-dentista na prevenção do vírus e as adaptações necessárias no ambiente odontológico. Material e método: Trata-se de uma revisão de literatura realizada através da análise de artigos contidos nas plataformas LILACS, PubMed e Medline que cumprissem o intuito informativo da pesquisa. Resultados: A partir dos dados obtidos, observou-se que a COVID-19 apresenta como principais sintomas clínicos febre, tosse, espirros e coriza, em casos brandos. As vias de transmissão mais frequentes são a direta e por contato. A fim de identificar casos suspeitos o cirurgião-dentista deve medir a temperatura corporal do paciente e aplicar um breve questionário. Todo o percurso do atendimento deverá ser planejado com o intuito de reduzir os riscos de contaminação, desde a escolha dos instrumentais que serão utilizados até a execução do procedimento. Conclusão: Portanto, no atual cenário da pandemia, surgem novos desafios aos quais os profissionais devem responder com constante cautela no que se refere à biossegurança, devida capacitação com periodicidade e ética. No entanto, reforça-se ainda mais a demanda por atualização constante dos protocolos, com base nas evidências científicas mais recentes, para minimizar os riscos de transmissão do vírus.

Descritores: Infecções por Coronavirus; Odontologia; Exposição a Agentes Biológicos.

\section{Abstract}

Introduction: In the face of the COVID-19 pandemic, the dental surgeon as well as other health professionals are the most exposed to the virus, which requires greater biosafety in care. Objective: Within this context, the present study aims to ass ess the challenges of dental practice in the face of the current pandemic scenario, emphasizing the role of the dentist in preventing the virus and the necessary adaptations in the dental environment. Material and method: This is a literature review carried out through the analysis of articles contained in the LILACS, PubMed and Medline platforms that fulfilled the informational purpose of the research. Results: From the data obtained, it was observed that COVID-19 presents as main clinical symptoms fever, cough, sneezing and runny nose, in mild cases. The most frequent routes of transmission are direct and contact. In order to identify suspected cases, the dentist must measure the patient's body temperature and apply a brief questionnaire. The entire course of care must be planned in order to reduce the risk of contamination, from the choice of instruments to be used to the execution of the procedure. Conclusion: Therefore, in the current scenario of the pandemic, new challenges arise to which professionals must respond with constant caution regarding biosafety, due to training with periodicity and ethics. However, the demand for constant updating of protocols is further reinforced, based on the most recent scientific evidence, to minimize the risks of virus transmission.

Descriptors: Coronavirus Infections; Dentistry; Exposure to Biological Agents.

\section{Resumen}

Introducción: Ante la pandemia de COVID-19, tanto el cirujano dentista como otros profesionales de la salud son los más expuestos al virus, lo que requiere una mayor bioseguridad en la atención. Objetivo: En este contexto, el presente estudio tiene como objetivo evaluar los desafíos de la práctica odontológica ante el actual escenario pandémico, enfatizando el papel del odontólogo en la prevención del virus y las adaptaciones necesarias en el entorno odontológico. Material y método: Se trata de una revisión de la literatura realizada a través del análisis de artículos contenidos en las plataformas LILACS, PubMed y Medline que cumplieron con el propósito informativo de la investigación. Resultados: A partir de los datos obtenidos, se observó que COVID-19 presenta como principales síntomas clínicos fiebre, tos, estornudos y moqueo, en casos leves. Las vías de transmisión más frecuentes son la directa y la de contacto. Para identificar los casos sospechosos, el dentista debe medir la temperatura corporal del paciente y aplicar un breve cuestionario. Se debe planificar todo el curso de la atención para reducir el riesgo de contaminación, desde la elección de los instrumentos a utilizar hasta la ejecución del procedimiento. Conclusión: Por tanto, en el escenario actual de la pandemia, surgen nuevos retos a los que los profesionales deben responder con constante cautela en materia de bioseguridad, debido a la formación con periodicidad y ética. Sin embargo, la demanda de una actualización constante de los protocolos se refuerza aún más, basada en la evidencia científica más reciente, para minimizar los riesgos de transmisión del virus.

Descriptores: Infecciones por Coronavirus; Odontología; Exposición a Agentes Biológicos.

INTRODUÇÃO

No final de 2019, na cidade de Wuhan, localizada na China foi descoberto e registrado casos do novo coronavírus (COVID-19). Diante da sua rápida disseminação, instalou-se um quadro de emergência de saúde pública de preocupação global. Nesse sentido, a atual pandemia de COVID-19 pertence a uma família de vírus de ácido ribonucleico (RNA) de fita simples, conhecidos como Coronaviridae ${ }^{1,2}$. Geralmente, os hospedeiros destes vírus são animais como camelos, gatos e morcegos, 
entretanto, alguns são capazes de infectar humanos, como o MERS-CoV, SARS-CoV e o SARS CoV-2, sendo este o agente etiológico da COVID $-19^{3}$.

Os principais sinais e sintomas da COVID-19 consistem em febre, apatia, mialgia, tosse seca, perda parcial ou total do olfato (hiposmia/ anosmia) e alteração ou redução e/ou perda total do paladar (disgeusia/hipogeusia/ageusia), insuficiência renal e doença respiratória aguda com necessidade de ventilação mecânica invasiva ${ }^{4}$. A perda do paladar e do olfato são sinais prodrômicos e devem ser abordados na anamnese pelo cirurgião-dentista. Ademais, é importante ressaltar que o espectro clínico da doença varia de infecções assintomáticas a quadros graves ${ }^{5}$.

Segundo o jornal New York Times, a odontologia é uma das profissões de maior risco de contágio à COVID-19. Dessa forma, tornouse fundamental a aplicação de um protocolo clínico nos consultórios odontológicos a fim de prevenir novas infecções e a propagação do vírus ${ }^{6}$.

$\mathrm{Na}$ prática clínica, os fluidos orais do paciente, a contaminação do material e as superfícies dos dentes podem ser fontes de contágio tanto para o dentista e auxiliar, como para o paciente. Além disso, gotículas de saliva e sangue depositadas nas superfícies ou inalação de aerossol por instrumentos rotativos e as peças de mão de ultrassom também constituem um risco de contágio. Logo, o uso de desinfetantes e equipamentos de proteção individual (EPI) continua sendo imprescindível para a prática odontológica correta ${ }^{7}$.

As medidas de biossegurança são essenciais para evitar a transmissão de microrganismos ${ }^{8}$. Diante da pandemia vigente de COVID-19, os cuidados com a prática odontológica se tornaram ainda mais importantes para que profissionais e pacientes estejam mais seguros e protegidos ${ }^{9}$.

Nessa perspectiva, o presente trabalho tem como objetivo analisar os desafios da prática odontológica frente ao cenário de pandemia atual, enfatizando a atuação do cirurgião-dentista na prevenção do vírus e as adaptações necessárias no ambiente odontológico.

MATERIAL E MÉTODO

Esse estudo trata-se de uma revisão de literatura do tipo narrativa, no qual se realizou uma seleção de artigos científicos nos idiomas português, inglês ou espanhol, publicados de 2000 a 2020, a partir das bases de dados: LILACS, PubMed e Medline. Nesse sentido, as palavras-chave utilizadas para pesquisa nas plataformas foram: Infecções por Coronavirus, Odontologia e Exposição a Agentes Biológicos.

Para seleção dos artigos os critérios de inclusão foram: (1) artigo completo, disponível para leitura; (2) revisões sistemáticas sobre o tema; (3) pesquisas referentes aos desafios da prática odontológica frente ao cenário de pandemia atual. Os critérios de exclusão por sua vez, foram: (1) artigos científicos publicados fora do intervalo de tempo estabelecido (2000 a 2020); (2) artigos publicados em outros idiomas que não sejam português, inglês ou espanhol. Inicialmente, foram escolhidos os artigos potencialmente elegíveis a partir da leitura do título e resumo. Por conseguinte, os artigos que se adequavam a temática proposta foram selecionados para uma leitura completa e posteriormente armazenados no programa de gerenciamento de referência Mendeley Desktop (versão 1.19.5). Os artigos completos foram lidos e, considerando os critérios propostos, foram coletadas informações do ano e periódico da pesquisa, tipo de estudo e informações importantes referentes ao atendimento odontológico durante a pandemia de COVID-19. Os dados foram agrupados e organizados de forma descritiva/narrativa em tópicos.

RESULTADOS E DISCUSSÃO

Após a aplicação dos critérios de inclusão, 32 artigos foram selecionados. Dentre as principais temáticas importantes sobre os desafios da prática odontológica frente ao cenário de pandemia atual foram selecionadas as seguintes:

- Transmissão do SARS-CoV-2 na prática odontológica

As principais vias de transmissão da COVID-19 consistem em tosse, espirro, gotículas contaminadas, contato com mucosa oral, nasal e olhos, podendo também ser transmitido entre indivíduos por meio de saliva e fluidos ${ }^{10}$. Geralmente, os sintomas apresentamse após uma semana, sendo principalmente tosse, febre, fadiga e congestão nasal. Pacientes idosos ou que apresentam comorbidades, como doenças cardiovasculares, hipertensão arterial, diabetes mellitus, pneumopatias, doenças neurológicas ou renais, imunodepressão, obesidade, asma e puérperas, constituem o grupo de risco da infecção ${ }^{11}$.

Tendo em vista o elevado risco de morbimortalidade, a Organização Mundial de Saúde (OMS), classificou também as gestantes como grupo de risco da COVID-19. Essas mulheres, quando infectadas, podem apresentar sintomas leves como tosse e febre até quadros mais graves como síndrome respiratória aguda grave (SARS), sendo geralmente maior o grau 
de complicação na segunda metade da gestação ${ }^{12}$. Nesse contexto, muitas gestantes temem problemas durante o período gestacional e no parto, como a possibilidade de transmissão

vertical do vírus. Ainda não há um consenso entre os estudos dessa temática: alguns identificam a possibilidade do aparecimento de sintomas análogos aos da mãe infectada no recém-nascido, enquanto outros acreditam que não há possibilidade de rompimento da barreira placentária ${ }^{13}$. Além disso, segundo a literatura, gestantes infectadas que evoluem para um quadro grave asssociado a comorbidade correm maior risco de parto prematuro ou uma cesariana de emergência, o que aumenta o risco de morte materna e neonatal ${ }^{14}$.

Os cirurgiões-dentistas, bem como os demais profissionais de saúde, estão mais propensos à contaminação e transmissão da infecção pela COVID-19. Isso se deve ao fato de que estão sujeitos a atender pacientes acometidos pelo coronavírus, sintomáticos ou assintomáticos, além da exposição a possíveis riscos no consultório odontológico ${ }^{15}$. Nesse sentido, na prática odontológica, o uso de alta rotação, instrumentos ultrassônicos, seringa de ar/água, entre outros, pode contaminar as superfícies e gerar aerossóis, sendo esta uma possível rota de transmissão do vírus, tanto para os profissionais como para os pacientes ${ }^{16}$.

É importante enfatizar que a saliva pode ser um reservatório da COVID-19, tendo em vista que constitui um meio que agrega secreções tanto da orofaringe, nasofaringe e pulmões, como também da região subgengival. Dessa forma, ainda que alguns procedimentos não produzam aerossóis, podem promover contaminação, na presença do vírus na saliva, na bolsa periodontal e no sangue ${ }^{17}$.

Diante da pandemia vigente, iniciou-se uma preocupação por parte dos cirurgiõesdentistas em relação à infecção cruzada e a possibilidade de propagação do vírus durante os procedimentos. Dessa forma, segundo as recomendações do Conselho Federal de Odontologia (CFO), os atendimentos deveriam restringir-se apenas para os casos de urgência e emergência. Assim, tratamentos odontológicos eletivos deveriam ser postergados $^{18}$.

De acordo com a American Dental Association (ADA), a emergência odontológica consiste em situações com possível risco de vida e que exigem tratamento imediato a fim de conter sangramento, dor severa ou infecção grave, como celulite, sangramento não controlado ou trauma. Por sua vez, a urgência odontológica trata casos que requerem atenção imediata para aliviar dores severas e/ou risco de infecção e, assim, reduzir o número de pacientes nos serviços de emergência ${ }^{19}$ (Tabela 1)

\begin{tabular}{|c|c|c|}
\hline EMERGÊNCIA & URGÊNCIA & ELETIVO \\
\hline $\begin{array}{l}\text {-Sangramento } \\
\text { descontrolado; } \\
\text { - Celulite ou infecção } \\
\text { difusa de tecidos moles } \\
\text { c } \\
\text { om potencial } \\
\text { comprometimento das } \\
\text { vias aéreas do paciente; } \\
\text { os Trauma envolvendo } \\
\text { os ossos da face com } \\
\text { potencial } \\
\text { comprometimento das } \\
\text { vias aéreas do paciente; }\end{array}$ & $\begin{array}{l}\text { - Pulpite irreversível; } \\
\text { - Pericoronite; } \\
\text { - Osteíte pós-operatória cirúrgica } \\
\text { ou troca de curativos de cavidade } \\
\text { seca; } \\
\text { - Abscesso ou infecção bacteriana } \\
\text { localizada, resultando em dor e } \\
\text { inchaço localizados; } \\
\text { - Fratura de dente resultando em } \\
\text { dor ou causando trauma nos } \\
\text { tecidos moles. } \\
\text { - Trauma dentário com avulsão / } \\
\text { luxação. } \\
\text { - Confecção de restauração } \\
\text { provisória caso a restauração for } \\
\text { perdida, quebrada ou esteja } \\
\text { causando irritação gengival. } \\
\text { - Cárie extensa ou restaurações } \\
\text { defeituosas que causam dor; } \\
\text { - Remoção de suturas; } \\
\text { - Ajustes da dentadura em } \\
\text { pacientes em radiação } \\
\text { tratamento oncológico; } \\
\text { - Mucosites; } \\
\text { - Ajustes ou reparos de próteses } \\
\text { quando a função é impedida; } \\
\text { - Substituição do preenchimento } \\
\text { temporário nas aberturas de } \\
\text { acesso endodôntico em pacientes } \\
\text { com dor; } \\
\text { - Ajustes em fios ou aparelhos } \\
\text { ortodônticos que perfuram ou } \\
\text { ulceram a mucosa. }\end{array}$ & $\begin{array}{l}\text { - Avaliações } \\
\text { odontológicas iniciais } \\
\text { ou de manutenção; } \\
\text { • Radiografias de } \\
\text { rotina; } \\
\text { - Profilaxias; } \\
\text { - Terapia periodontal } \\
\text { de rotina; } \\
\text { • Procedimentos } \\
\text { ortodônticos diferentes } \\
\text { daqueles para tratar de } \\
\text { problemas agudos (por } \\
\text { exemplo, dor, infecção, } \\
\text { trauma); } \\
\text { - Extração de dentes } \\
\text { assintomáticos; } \\
\text { - Restaurações, } \\
\text { incluindo tratamento } \\
\text { de lesões cariosas } \\
\text { assintomáticas; } \\
\text { •Procedimentos } \\
\text { odontológicos estéticos. }\end{array}$ \\
\hline
\end{tabular}

- A conduta do cirurgião-dentista frente à COVID-19

A pandemia do SARS-CoV-2 fez com que muitos profissionais de saúde modificassem seus atendimentos, entre eles o cirurgiãodentista. Este momento proporcionou mudanças na Odontologia, ocasionando uma alteração expressiva na forma de atendimento e rotina dos consultórios odontológicos ${ }^{20}$. Sendo 0 cirurgião-dentista um profissional que frequentemente está em contato com fluidos corporais (saliva e sangue) dos seus pacientes, ele pode agir como um vetor, correndo risco de ser contaminado e/ou transmitindo a contaminação para outras pessoas. Para continuar exercendo sua profissão com segurança foi necessária uma adaptação as novas medidas de saúde. Acredita-se que a transmissão do COVID-19 é interpessoal e ocorre principalmente por meio de gotículas respiratórias e transmissão por contato ${ }^{21}$.

As medidas preconizam manter um ambiente de atendimento adequado e oferecer um tratamento seguro, seguindo as medidas de proteção e evitando que os pacientes corram risco de se contaminar. Nesse sentido, a maioria dos instrumentais odontológicos podem facilmente contaminar o paciente, pois eles entram em contato direto com a saliva. Dessa forma, o próprio jato de uma peça de alta rotação tem a capacidade de espalhar gotículas de água para o ambiente, cobrindo o local com os microrganismos presentes na cavidade oral do paciente ${ }^{22}$. 
Os novos cuidados dizem respeito à paramentação do profissional, a adequação do local de atendimento e a conduta adequada para com o paciente.

\section{- Paramentação e cuidados do profissional}

A lavagem das mãos deve ser realizada de maneira cuidadosa, pois a contaminação das mãos com o vírus e sua posterior inoculação nas mucosas oral, nasal e ocular representa uma via de transmissão importante. A lavagem com água e sabão deve ser criteriosa, e de duração entre 30-60 segundos, deve ser realizada antes e após os atendimentos e também pode ser realizada com álcool em gel a $70 \%$ se não estiverem com sujidade visível ${ }^{9}$.

Um estudo realizado no hospital municipal de Várzea, Minas Gerais identificou que a maioria dos profissionais da saúde que ali atuavam utilizavam tempo menor que 0 necessário para realizar a higienização das mãos. O tempo médio para higienização com água e sabão é de 40 a 60 segundos para remover os microrganismos que colonizam as camadas superficiais da pele, já o álcool leva de 20 a 30 segundos, para reduzir a carga microbiana das mãos ${ }^{23}$.

O Equipamento de Proteção Individual (EPI), que inclui máscaras, luvas, aventais, jalecos, gorros e óculos ou protetores faciais, é definido pela Norma Regulamentadora n6 como sendo todo dispositivo ou produto, de uso individual utilizado pelo trabalhador, destinado à proteção de riscos suscetíveis de ameaçar a segurança e a saúde no trabalho ${ }^{24}$. Em meio a pandemia tornou-se mais comum 0 uso do protetor facial/viseira para garantir uma proteção mais ampla da região da face, porém o protetor deve passar pelo processo de desinfecção a cada paciente atendido e seu uso não substituiu - uso da máscara, que deve ser utilizada por baixo da viseira ${ }^{9}$.

\section{- Cuidados ao receber o paciente}

É importante ter um protocolo de atendimento para avaliar as condições de saúde do paciente antes do seu atendimento no consultório, pois algumas informações básicas podem auxiliar na identificação de pessoas com suspeita de contaminação. Um breve questionário com perguntas objetivas pode ser preenchido para avaliar se o paciente pode ou não ser atendido. Devido à pandemia e a tentativa de minimizar o contato interpessoal, essas informações estão sendo coletadas por meio digital. A tabela 2 a seguir foi montada com base em um questionário elaborado pelo Conselho Regional de Farmácia $(\mathrm{CRF})^{25}$, e aborda as principais questões a serem avaliadas sobre o COVID-19.
Tabela 2: principais questões para identificar pacientes com suspeita de COVID-19 (Fonte: CRF, 2020 ${ }^{25}$ ).

\begin{tabular}{l|l}
\hline PERGUNTAS & RELEVÂNCIA DA INFORMAÇÃo \\
\hline Apresenta algum sintoma? & $\begin{array}{l}\text { Sintomas como tosse, febre, cansaço, coriza, dor de } \\
\text { garganta, apatia, mialgia, perda parcial ou total do } \\
\text { olfato e/ou do paladar, insuficiência renal e doença } \\
\text { respiratória aguda com necessidade de ventilação } \\
\text { mecânica invasiva. São todos sintomas da doença. }\end{array}$ \\
\hline $\begin{array}{l}\text { Viajou para fora do país } \\
\text { recentemente? }\end{array}$ & $\begin{array}{l}\text { Como se trata de uma pandemia que está afetando } \\
\text { diversos países é importante saber se o paciente } \\
\text { não fez nenhuma viagem nos últimos 14 dias } \\
\text { (período de incubação do vírus). }\end{array}$ \\
\hline $\begin{array}{l}\text { Teve contato com alguém } \\
\text { com COVID-19? }\end{array}$ & $\begin{array}{l}\text { Algumas pessoas que são contaminadas podem não } \\
\text { desenvolver os sintomas, mas ainda assim elas } \\
\text { podem transmitir a doença. }\end{array}$ \\
\hline $\begin{array}{l}\text { Faz parte do grupo de } \\
\text { risco? }\end{array}$ & $\begin{array}{l}\text { Os cuidados devem sem ainda maior com as } \\
\text { pessoas que fazem parte desse grupo, pois o risco } \\
\text { de complicações é maior. }\end{array}$ \\
\hline $\begin{array}{l}\text { Esta grávida, em qual } \\
\text { trimestre? }\end{array}$ & $\begin{array}{l}\text { Além de ainda não ter sido identificado se a } \\
\text { gestante pode transmitir o vírus para o feto, } \\
\text { possíveis complicaçóes podem afetar o período } \\
\text { gestacional. }\end{array}$ \\
\hline
\end{tabular}

É importante salientar que o objetivo do questionário é meramente informativo e de forma alguma deve substituir qualquer exame médico. Os questionários são uma maneira simples e rápida de coletar informações e fazer avaliações instantâneas.

Outro detalhe a ser evitado é a aglomeração de pessoas. Realizar as marcações por meio digital e em horários espaçados, está sendo um dos meios mais eficientes na tentativa de evitar que os pacientes fiquem aguardando na recepção. Aglomerações são contrárias as orientações do Ministério da Saúde e da Organização Mundial da Saúde (OMS), que reiteram que o isolamento social reduz a curva de contágio e surgimento de novos casos ${ }^{26}$.

O paciente deve ter sua temperatura medida e acesso facilitado a mecanismos de descontaminação das suas mãos assim que entrar no consultório. A temperatura deverá ser aferida, preferencialmente, com termômetro digital de testa $e$ deve ser rotina nos atendimentos aos pacientes ${ }^{9}$. A higienização por meio da lavagem constante e de maneira correta com água e sabão e/ou a utilização de desinfetantes a base de álcool, principalmente soluções etanólicas ou isopropílicas, são os métodos mais recomendados ${ }^{27}$.

Além dessa atenção com relação ao paciente, também é importante fazer a higienização do local após o atendimento. É necessário higienizar 0 chão, bancadas, cadeiras e todos os objetos e locais onde o paciente anteriormente atendido esteve em contato. Muitos produtos podem ser utilizados para realizar essa descontaminação, a OMS recomenda duas formulações alcoólicas de simples preparação e fácil uso, sendo uma a base de etanol $80 \%$ e a outra de isopropanol $75 \%{ }^{27}$.

- Adaptações no ambiente clínico e durante o atendimento odontológico

Considerando que o SARS-CoV-2 foi 
recentemente identificado na saliva de pacientes infectados, é importante que os cirurgiões-dentistas se preocupem com a disseminação de doenças infecciosas respiratórias, principalmente referentes a formação de aerossóis durante 0 atendimento odontológico ${ }^{20,28}$. Todo o atendimento deve ser planejado com o intuito de minimizar os riscos de contaminação, desde a escolha dos instrumentais que serão utilizados até a execução do procedimento.

O cirurgião-dentista deve estar completamente paramentado com seus EPI (máscara, gorro, óculos, protetor facial, avental impermeável descartável, luvas e outros). É preferível que se utilize instrumentos manuais ao invés de rotatórios, não deve usar a seringa tríplice, substituir a irrigação com seringa com soro fisiológico; evitar a utilização da cuspideira, preferindo aspirar a cavidade oral do paciente com mais frequência, usar isolamento absoluto e optar por procedimentos que não gerem dispersão de gotículas de água, como tratamento restaurador atraumático e restaurações provisórias ${ }^{29,30}$.

O uso da caneta de alta rotação está sendo questionado por diversos autores. Em um estudo realizado por Montalli et al. ${ }^{31}$ foi identificado a capacidade de dispersão de gotículas de água causada pelo uso da alta rotação com e sem uma barreira individual de biossegurança odontológica. $\mathrm{Na}$ ausência da barreira as gotículas alcançaram uma distância de aproximadamente $150 \mathrm{~cm}$ e com a barreira apenas $4 \%$ dessas gotículas chegaram a essa distância. Ele concluiu que essa barreira pode ser uma alternativa viável para auxiliar nos atendimentos, no entanto sempre que possível deve ser utilizada a caneta de baixa e sem spray de água.

A desparamentação dos EPI é um momento crítico e deve ser realizada de forma correta para evitar contaminação inadvertida. A desparamentação e os cuidados inadequados com os EPI são a principal causa de contaminação entre profissionais da saúde ${ }^{32}$. Seguindo todas as recomendações estabelecidas pelos órgãos de saúde é possível realizar um atendimento odontológico seguro e sem risco de contaminação.

CONSIDERAÇÕES FINAIS

Mediante a compreensão que o cirurgião-dentista como profissional da saúde não está isento de um novo olhar sobre as complexidades que o atual cenário de nível mundial poderá impactar diretamente ou indiretamente sobre um ambulatório odontológico, torna-se necessário que os profissionais estejam alinhados não somente à biossegurança como também aos direcionamentos de conduta preconizados pela Organização Mundial de Saúde (OMS). REFERÊNCIAS

1. Ather A, Patel B, Ruparel NB, Diogenes A, Hargreaves KM. Coronavirus disease 19 (COVID-19): implications for clinical dental care. J Endod. 2020May;46(5):584-95.

2. Sabino-Silva R, Jardim ACG, Siqueira WL. Coronavirus COVID-19 impacts to dentistry and potential salivary diagnosis. Clin.Oral Investig. 2020;24:1619-21.

3. Sohrabi C, Alsafi Z, O'Neill N, Khan M, Kerwan A, Al-Jabir A, et al. World Health Organization declares global emergency: A review of the 2019 novel coronavirus (COVID-19). Int J Surg. 2020;76:71-6.

4. Zhu N, Zhang D, Wang W, Li X, Yang B, Song $J$, et al. China Novel Coronavirus Investigating and Research Team. A Novel Coronavirus from Patients with Pneumonia in China, 2019. N Engl J Med. 2020;382(8):727-33.

5. Bai Y, Yao L, Wei T, Tian F, Jin DY, Chen L, et al. Presumed Asymptomatic Carrier Transmission of COVID-19. JAMA. 2020;323(14):1406-7.

6. Gamio L. The Workers Who Face the Greatest Coronavirus Risk. New York Times, 15 March 2020. Available from: https://www.nytimes.com/interactive/2020/03/15 /business/economy/coronavirus-workerrisk.html (accessed on 5 April 2020).

7. Luzzi V, lerardo $G$, Bossù $M$, Polimeni $A$. COVID-19: Pediatric Oral Health during and after the Pandemics. Preprints. 2020; 2020040002:1-10.

8. World Health Organization - WHO. Coronavirus disease (Covid-19) outbreak. Geneva: World Health Organization; 2020[acesso 13 maio 2020]. Disponível em: https://www.who.int/csr/don/12-january-2020novel-coronavirus-china/en/.

9. Tuñas ITC, Silva ET, Santiago SBS, Maia KD, Silva-Júnior GO. Doença pelo Coronavírus 2019 (COVID-19): Uma Abordagem Preventiva para Odontologia. Rev Bras Odontol. 2020;77: 1-7.

10. Velavan TP, Meyer CG. The COVID-19 epidemic. Trop Medlnt Health. 2020;25(3): 278-80.

11. Lana RM, Coelho FC, Gomes MFC, Cruz OG, Bastos LS, Villela DAM, et al. Emergência do novo coronavírus (SARS-CoV-2) e o papel de uma vigilância nacional em saúde oportuna e efetiva. Cad Saúde Pública - Perspectivas. 2020;36(3):e00019620.

12.Zaigham M,Andersson O. Maternal and Perinatal Outcomes with Covid-19: a systematic review of 108 pregnancies. Acta Obst Gynecol Scand. 2020;99(7):823-29. 
13. Hoffmann M, Weber HK, Schroeder S, Krüger $\mathrm{N}$, Herrler T, Erichsen S, et al. SARS-CoV-2 Cell Entry Depends on ACE2 and TMPRSS2 and Is Blocked by a Clinically Proven Protease Inhibitor. Cell. 2020;181(2):271-80.

14. Li N, Han L, Peng M, Lv Y, Ouyang Y, Liu K, et al. Maternal and neonatal outcomes of pregnant women with COVID-19 pneumonia: a casecontrol study. Clin Infect Dis. 2020;71(16): 2035-41.

15. Fini MB. Oral saliva and COVID-19. Oral Oncol. 2020;108:104821.

16. Hamid H, Khurshid Z, Adanir N, Zafar MS, Zohaib S. COVID-19 Pandemic and Role of Human Saliva as a Testing Biofluid in Point-ofCare Technology. Eur J Dent. 2020;14(S1): S123-29.

17. Dar Odeh N, Babkair H, Abu-Hammad S, BorzangyS,Abu-Hammad A, Abu-Hammad O. COVID-19: Present and Future Challenges for Dental Practice. Int J Environ Res Public Health. 2020;17(9):3151.

18. Associação de Medicina Intensiva Brasileira. Conselho Federal de Odontologia. Recomendações A, para atendimento odontológico COVID C. Comitê de Odontologia AMIB/CFO de enfrentamento ao COVID-19. Departamento de Odontologia AMIB-1. Atualização 25/03/2020. São Paulo: AMIB; 2020.

19. American Dental Association (ADA) - ADA develops guidance on dental emergency, nonemergency care - Recommendations part of dentiss response over COVID-19 concerns. March, 18, 2020. Acesso em: https://www.ada.org/en/publications/adanews/2020-archive/march/ada developsguidance-on-dental-emergency nonemergencycare.

20. Franco JB, Camargo AR, Peres MPSM. Cuidados Odontológicos na era do COVID-19: recomendações para procedimentos odontológicos e profissionais. Rev Assoc Paul Cir Dent. 2020;74(1):18-21.

21. The Chinese Preventive Medicine Association. An update on the epidemiological characteristics of novel coronavirus pneumonia (COVID-19). Chin J Epidemiol. 2020;41(2): 139-44.

22. Hua LMF, Bian Z. Coronavirus Disease 2019 (COVID-19): Emerging and Future Challenges for Dental and Oral Medicine. J Dent Res. 2020; 99(5):481-87.

23. Mota EC, Barbosa DA, Silveira BRM, Rabelo TA, Silva NM, Silva PLN, et al. Higienização das mãos: uma avaliação da adesão e da prática dos profissionais de saúde no controle das infecções hospitalares. Rev Epidemiol Control Infect. 2014;4(1):12-7.

24. Brasil. Ministério do Trabalho e Emprego.
Norma Regulamentadora ํo 6 - Equipamento de Proteção Individual. Publicação D.O.U. Portaria SIT no 25, de 15 de outubro de 2001.

25. Conselho Regional de Farmácia. Ficha de Atendimento Farmacêutico - Suspeita de COVID-19. Atualização 17/08/2020. São Paulo: CFF; 2020. Acesso em: http://www.crfsp.org.br/images/arquivos/Ficha atendimento_coronavirus.pdf.

26. Oliveira TM. Manifestações e aglomerações em períodos de pandemia por COVID-19 Manifestações em períodos de pandemia. InterAm J Med Health. 2020;30(9):e202003025.

27. Siqueira R, Lenz GF, Silva FJLB, Silva FR. Soluções a base de álcool para higienização das mãos e superfícies na prevenção da covid19: compêndio informativo sob o ponto de vista da química envolvida. Quím Nova. 2020;43(5): 679-84.

28. Peng X, Xu X, Li Y, Cheng L, Zhou X, Ren B. Transmission routes of 2019-nCoV and controls in dental practice. Int J Oral Sci. 2020;12(1):9.

29. Haines A, de Barros EF, Berlin A, Heymann DL, Harris MJ. National UK programme of community health workers for COVID-19 response. Lancet. 2020;6736(20)30735-2.

30. Long Y, Hu T, Liu L, Chen R, Guo Q, Yang L et al. Effectiveness of N95 respirators versus surgical masks against influenza: A systematic review and meta-analysis. J Evid Based Med. 2020;1-9.

31. Montalli VAM, Garcez AS, Montalli GAM, França FMG, Suzuki SS, Mian LMT et al. Individual biosafety barrier in dentistry: an alternative in times of covid-19. Preliminary study. RGO. 2020;68:e20200088.

32. Guimarães HP, Damasceno MC, Ribera JM, Onimaru A, Malvestio $M$, Bueno $M$, et al. Recomendações para 0 atendimento de pacientes suspeitos ou confirmados de infecção pelo novo coronavírus (SARS-CoV-2) pelas equipes de atendimento pré-hospitalar móvel. ABRAMED - Associação Brasileira de Medicina Diagnóstica. 2020.

\section{CONFLITO DE INTERESSES}

Os autores declaram não haver conflitos de interesse

\section{AUTOR PARA CORRESPONDÊNCIA}

\section{Ana Beatriz Rodrigues Moura}

Curso de Graduação em Odontologia. Centro de Saúde e Tecnologia Rural, Universidade Federal de Campina Grande (UFCG)

58708-110 Patos - PB, Brasil

E-mail: ana_beatriz_882@hotmail.com

Submetido em 26/02/2021 Aceito em 16/07/2021 